\title{
CONFORTO TÉRMICO EM FORTALEZA-CE
}

\author{
Marcelo de Oliveira Moura \\ Prof. Universidade Federal da Paraíba \\ geommoura@yahoo.com.br \\ Maria Elisa Zanella \\ elisazv@terra.com.br \\ Marta Celina Linhares Sales \\ mclsales@uol.com.br
}

Resumo

O trabalho consiste em investigar as condições do conforto térmico em ambientes externos da cidade de Fortaleza tendo como orientação teórica Monteiro (1976). A análise do conforto na cidade ocorreu por meio da realização de campanhas sob condições sazonais diferenciadas, representativas da habitualidade climática da região, em doze pontos distintos da realidade intra-urbana da metrópole. Duas escalas foram utilizadas para a investigação do ritmo horário do conforto térmico: índice de temperatura efetiva (Te) e o Diagrama do INMET. Os resultados revelam que é a partir das 9 horas que se configura o desconforto pela cidade, condição essa que se estende até as 17 horas. Em todos os pontos experimentais os horários de $14 \mathrm{e}$ 15 horas são os mais críticos para o parâmetro Te. Nos períodos da noite e madrugada, de forma geral, ocorreu condição de conforto.

Palavras-chave:Análise horária, conforto térmico, Fortaleza/CE.

\section{INTRODUÇÃO}

O clima produzido pela cidade pode afetar diretamente a saúde e o bem estar do homem, sendo possível, distinguir, nesta influência, inúmeras variáveis, dentre as quais o complexo térmico, que é formado pela temperatura do ar, temperatura radiativa, velocidade dos ventos e umidade. Estes atributos climáticos estão diretamente ligados ao conforto térmico (ANDRADE, 2005) e, portanto, à qualidade de vida.

O conforto térmico, deveria se constituir, assim, em um objetivo chave na intervenção do espaço urbano. Contudo, os gestores públicos pouco consideram as questões de ordem climática no planejamento das cidades, principalmente naquelas localizadas nas regiões tropicais.

Como na grande maioria das cidades localizadas em baixas latitudes, a exploração da temática aqui apresentada ainda é pouco desenvolvida também para a cidade de Fortaleza. Os estudos já existentes na metrópole foram desenvolvidos pela arquitetura com enfoque no conforto habitacional (HISSA, 2000). No entanto já houve o direcionamento das análises para o ambiente externo, ou seja, espaço público (SANTANA, 2002). Apesar disso, os trabalhos que concebem essa escala de análise, não avançaram no sentido de considerar a realidade intra-urbana e nem tampouco a dinâmica atmosférica regional atuante sobre a cidade em distintas realidades horárias e sazonais.

Revista da ANPEGE. v. 6, 2010 (jan./dez.)

p. $177-189$ 
Observar essas variáveis é essencial para uma investigação mais profunda do clima urbano da cidade e desse modo das alterações nas variáveis meteorológicas provocadas pela urbanização, os quais formam fatores limitantes na produção do conforto térmico no ambiente urbano. Os estudos que consideram apenas dados secundários oriundos das séries históricas realizados na maioria das vezes, em um único ponto amostral - o próprio posto de coleta oficial da cidade - dificilmente representarão a realidade das condições de conforto do espaço urbano.

O conforto térmico na cidade de Fortaleza será tratado neste artigo na perspectiva da espacialização dessa variável, tendo como referência a aplicação de duas escalas sob condições climáticas sazonais diferenciadas, geradas por meio de atributos climáticos coletados em áreas representativas da realidade urbana do município em forma de campanhas experimentais.

\section{CONFORTO TÉRMICO: aspectos conceituais}

De acordo com Frota \& Schiffer (1988), Santana (2002), Hissa (2000) e Buriol et al (2004) a análise do conforto climático ocorre por meio de índices sendo esses classificados em diferentes aspectos como: 1) índices biofísicos, que se baseiam nas trocas de calor entre o corpo e o ambiente, correlacionando os elementos do conforto com as trocas de calor que dão origem a esses elementos; 2) índices fisiológicos, que se baseiam nas reações fisiológicas originadas por condições conhecidas de temperatura seca do ar, temperatura irradiante média, umidade do ar e velocidade do vento e 3) índices subjetivos, que se baseiam nas sensações subjetivas de conforto experimentadas em condições em que os elementos de conforto térmico variam.

Existem vários índices ou escalas de conforto térmico, referentes à aplicação de condições ambientais de construção e de representação geográfica. As mais utilizadas no âmbito da climatologia geográfica são os índices de Temperatura Efetiva (Te) de Thom da década de 1950 e de Desconforto (Id) de Nieuwolt (1977) expressos por equações e mais recentemente um índice em forma de nomograma divulgado pelo INMET (Instituto Nacional de Meteorologia).

A escala da Temperatura Efetiva (Te), adotada nesta pesquisa, é do tipo fisiológico e determina o alcance das zonas de conforto para os adultos vestidos e em repouso, com um leve movimento do ar. $\mathrm{O}$ índice estabelece uma zona de conforto térmico entre $18.9^{\circ} \mathrm{C}$ e $25.6^{\circ} \mathrm{C}$. Essa escala é a mais usada nos trabalhos de climatologia urbana do Brasil, porém restam dúvidas quanto a sua validade nas cidades tropicais de clima quente-úmido, pois tal equação foi devidamente testada apenas nos países temperados. Quanto ao índice do Desconforto (Id) esse é expresso por: $\mathrm{Id}=0,5 \mathrm{Td}+(\mathrm{Td} \mathrm{UR}) / 500$, onde $\mathrm{Td}$ é a temperatura do bulbo seco medido em ${ }^{\circ} \mathrm{C}$ e UR a umidade relativa do ar. Para Buriol et al (2004), o valor Id igual a $21^{\circ} \mathrm{C}$ corresponde à condição ambiental mais agradável. Quando $26^{\circ} \mathrm{C}>\mathrm{Id}>24^{\circ} \mathrm{C}$ trata de uma situação de desconforto.

Já as escalas mais utilizadas para obtenção do conforto bioclimático se destacam a Carta Bioclimática de Olgyay de 1952 (FROTA \& SCHIFFER 1988: 18), o índice de Temperatura Efetiva de Yaglow e Hughtem do ano de 1923, a "Carta Bioclimática de Givoni" da década de 1970 e a escala do Conforto Térmico de Fanger (HISSA, 2000; SANTANA, 2002). Frota \& Schiffer (1988) apresentam outra escala que também se inseri nos índices biofísicos denominada de I.C.E. (Índice do Conforto Equatorial) desenvolvido por Webb na década de 1960 a qual determina as condições de conforto para habitantes de climas tropicais (testados na população de Cingapura). Frota \& Schiffer (1988:19) afirmam que há eficácia desse índice quando aplicado aos habitantes de regiões climáticas semelhantes a Cingapura, como é o caso da Amazônia. 
Seria o índice do Conforto Equatorial mais compatível a realidade climática das cidades brasileiras do que a Temperatura Efetiva de Thom ? Parece que não há registros da aplicação do I.C.E. em trabalhos de climatologia geográfica no país. Isso talvez seja explicado pela grande circulação nas academias da obra de Ayoade (1996), traduzida para o português, a qual apresenta o índice de Thom, que foi difundido em quase todos os estudos de geografia que abordam o conforto térmico nas cidades.

Santana (2002) relata uma nova estratégia de avaliar as condições de sensação térmica tendo como base o princípio adaptativo que diz: se uma mudança ocorre de forma a produzir desconforto, as pessoas reagem de forma a restaurar seu conforto. Esse princípio foi desenvolvido pelos ingleses Humphreys e Nicol e subsidiou novas formas de observação direta (percepção dialética), formas que consideram aspectos subjetivos do comportamento dos indivíduos, valorizando desse modo o componente psicológico do conforto. Esse método é conhecido como Modelo Adaptativo ou Conforto Térmico Adaptativo.

Discutindo a importância que os índices térmicos considerem o caráter adaptativo às sensações térmicas desenvolvido pelos homens, Roriz (2003) testou as modificações propostas por Humphereys e Nicol nas equações de Fanger, aplicando-as em duas cidades brasileiras: Campos do Jordão (SP) e Fortaleza (CE), na tentativa de mostrar que nas situações onde as oportunidades adaptativas sejam possíveis e adequadas, a zona de conforto pode ser ampliada.

Uma maior atenção deve ser dada à variável velocidade do vento, elemento geralmente desconsiderado nas pesquisas sobre conforto climático urbano no Brasil. No caso das cidades do nordeste brasileiro a latitude é a responsável por intensas taxas de insolação o que promove altas temperaturas que quando somado ao fator urbanização provoca um aumento do desconforto térmico nessas áreas urbanas. $O$ vento é a variável meteorológica de primeira ordem para a promoção do conforto climático urbano, porém, é o elemento mais alterado pela urbanização. Para exemplificar esse cenário temos a cidade de Fortaleza com uma redução aproximada de $50 \%$ da variável velocidade do vento (XAVIER, 2001) e a diferença dessa diminuição chega à ordem de $3 \mathrm{~m} / \mathrm{s}$ em setores mais urbanizados da cidade (MAIA ET AL, 1996).

Os pesquisadores de climatologia urbana precisam atentar para a questão da escolha de índices de conforto que melhor se adaptem à investigação do clima urbano em cidades tropicais, isso por que o maior número de pesquisas se volta para a análise das condições de conforto térmico em ambientes urbanos de climas temperados e em ambientes internos.

\section{CONFORTO TÉRMICO EM FORTALEZA: bases teóricas e metodológicas}

A concepção teórica adotada nesse trabalho segue as orientações de Monteiro (1976), onde concebe o Sistema Clima Urbano (S.C.U) um sistema singular, aberto, evolutivo, dinâmico, adpatativo e possível de auto-regulação que engloba o clima local e sua urbanização. Os níveis que formam a estrutura do S.C.U. podem ser representados por três canais de percepção humana: Canal I- Conforto Térmico; Canal II- Qualidade do Ar; Canal III- Impacto Meteórico que se associam, respectivamente, aos seguintes níveis de resolução do sistema: termodinâmico, físico-químico e hidrometeórico. Neste artigo é adotado o nível Termodinâmico (Canal I - Conforto Térmico) como suporte teórico para as considerações sobre o conforto térmico na cidade de Fortaleza.

O levantamento das condições do conforto térmico urbano foi obtido em áreas distintas da cidade, que apresentam dinamismo, estrutura urbana e condições geoecológicas diferenciadas. Para isso foi considerado material cartográfico específico do sítio da cidade (Hipsometria, Declividade, Cobertura Vegetal, Recursos Hídricos, cartas Percentual de Domicílios - Apartamentos/Residências e Densidade Populacional) em escala de 1:80.000 (FORTALEZA, 2006) e aspectos da morfologia e da função urbana

Revista da ANPEGE. v. 6, 2010 (jan./dez.) 
observados in situ (rugosidade, porosidade, permeabilidade, tipologia das vias). Todos esses preditores do sítio urbano da cidade formam o que se denomina de controles climáticos urbanos e que em associação aos elementos meteorológicos locais, intitulados de atributos climáticos urbanos, caracteriza o clima da cidade e consequentemente o conforto térmico.

Com base nos controles climáticos urbanos e considerando aspectos de operacionalização de campo foi definida uma malha de doze pontos para o estudo do conforto térmico (Figura 1). Seguido da seleção dos pontos de coleta, realizou-se dois experimentos com perfis de 24 horas ininterruptas (7 às 6 horas) com registros simultâneos em regimes sazonais diferenciados. $\mathrm{O}$ primeiro realizado no outono austral, período da quadra chuvosa na região, nos dias 04 e 05/05/2007 e o segundo na primavera, período da quadra seca, nos dias 09 e 10/11/2007. Oito variáveis foram mensuradas: temperatura e umidade relativa do ar, velocidade e direção dos ventos, nebulosidade, tipologia de nuvens, fluxo de veículos e pessoas. Essas variáveis foram necessárias para aplicação e análise das escalas de conforto utilizadas na pesquisa.

Ficura 23 - Loegizecgo dos portos experinertais de pesquizo

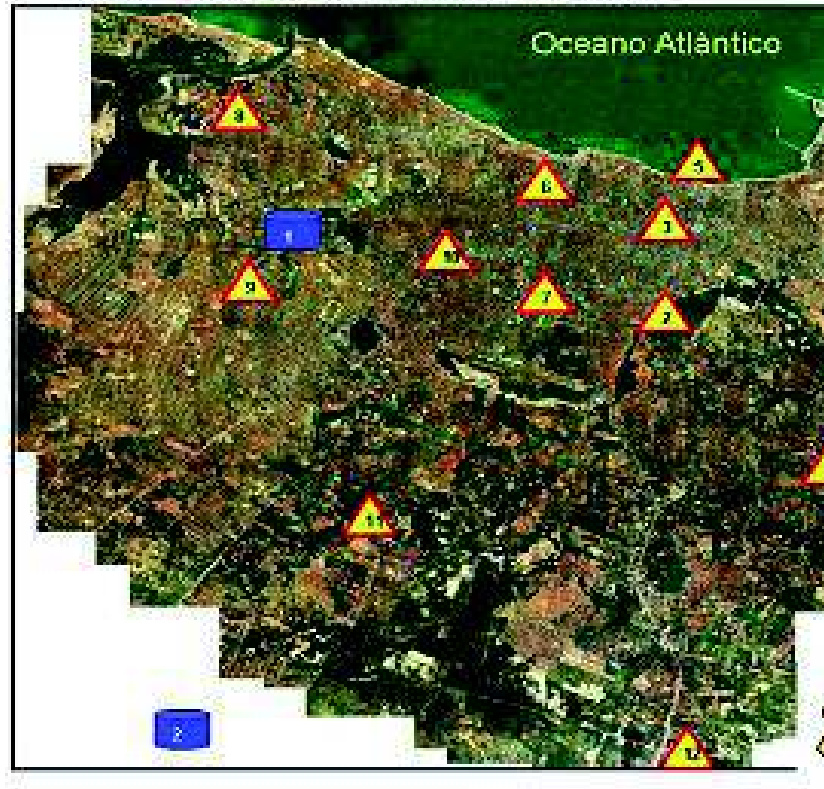

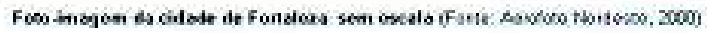

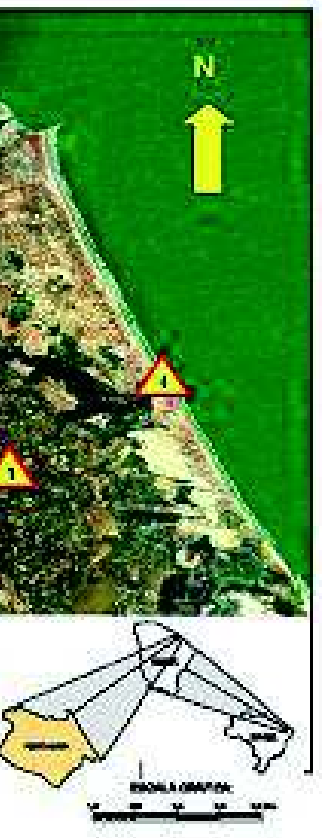

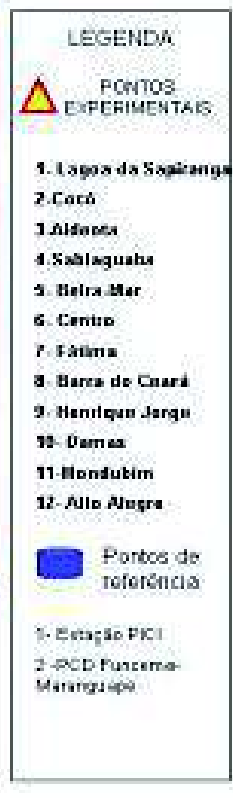

Figura 1- Localização das áreas experimentais da pesquisa

$\mathrm{Na}$ escala da temperatura efetiva (Te) utilizou-se uma fórmula desenvolvida por Thom no final da década de 1950 e apresentada por Ayoade (1996: 65): Te $=0.4$ x $(\mathrm{Td}+\mathrm{Tw})+4,8$ onde, Td e Tw são as temperaturas do bulbo seco e do bulbo úmido medidos em ${ }^{\circ} \mathrm{C}$, respectivamente. A faixa de conforto dessa escala, como já apresentada, está no intervalo de $18,9^{\circ} \mathrm{C}$ e $25,6^{\circ} \mathrm{C}$, sendo que os valores abaixo de $18,9^{\circ} \mathrm{C}$ e acima de $25,6^{\circ} \mathrm{C}$ são considerados, respectivamente, faixas de estresse ao frio e ao calor. Nesta 
pesquisa considerou-se a zona de Malhotra (AYOADE, 1996: 66), onde a Te varia de $21^{\circ} \mathrm{C}$ a $26^{\circ} \mathrm{C}$, já aplicada na Índia, onde as condições climáticas são mais próximas as de Fortaleza.

Outra escala considerada nesta pesquisa é o índice do conforto humano obtido através do Diagrama do Conforto Humano, fornecido pelo INMET (Figura 2). Nesse a temperatura do ar aparece na ordenada e umidade relativa do ar na abscissa, que por cruzamento define três zonas de conforto, sendo a velocidade do vento o elemento limitante para o condicionamento ao conforto térmico.

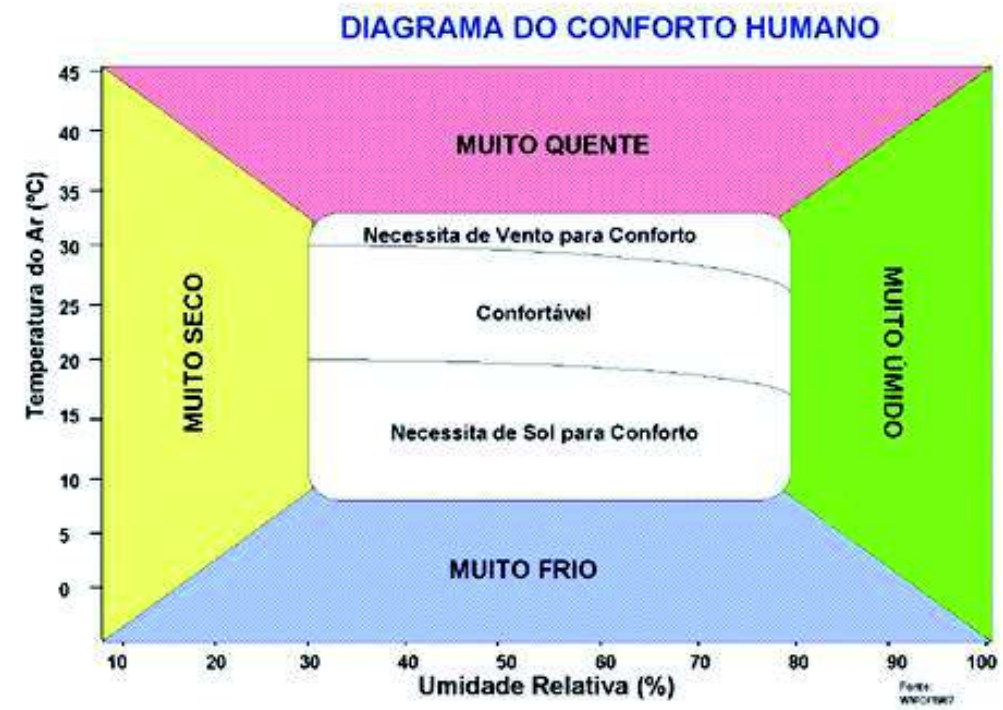

Figura 2- Diagrama do Conforto Humano- INMET

Fonte: INMET (2006)

\section{ANÁLISE SAZONAL DO CONFORTO TÉRMICO EM FORTALEZA SOB O ENFOQUE DO RITMO HORÁRIO}

As condições de conforto serão averiguadas separadamente, em quatro categorias de análise: manhã ( 7 às 12 horas), tarde (13 às 18 horas), noite (19 as 0 hora) e madrugada (1 às 6 horas), para uma melhor compreensão do ritmo diário desse atributo. Sumariamente pode-se afirmar o seguinte cenário do conforto térmico para a cidade de Fortaleza, considerando os episódios experimentais representativos da habitualidade climática do município:

\section{EXPERIMENTO I (Outono austral, representativo da quadra chuvosa)}

\section{Período manhã (7 às 12 horas)}

As escalas de conforto (Quadro 1 A e B) apresentam certa harmonia no confronto de seus valores durante esse período. Entre as 9 e10 horas encontra-se na zona de conforto apenas as áreas de Fátima, 
Cocó e Aldeota. As 11 e 12 horas já se manifesta desconforto para todas as áreas da pesquisa, necessitando, dessa forma, de vento para a promoção do conforto.

A partir das $9 \mathrm{~h}$ torna-se nítido o desconforto térmico em todas as áreas de análise do estudo, condição que se estende ate às $17 \mathrm{~h}$. A Sabiaguaba apresenta-se com essa situação até às $20 \mathrm{~h}$. Quando se observa o índice da temperatura efetiva- Te (Quadro 1A), já é detectável condição de desconforto nos registros de 7 e 8 horas para a Sabiaguaba e Barra do Ceará. Os demais pontos se enquadram dentro da zona de conforto dessa escala para esses horários. Entretanto a partir das $9 \mathrm{~h}$, como registrado também pela escala do INMET, todos os pontos experimentais estão condicionados à zona de desconforto, situação essa que se prolonga até as $12 \mathrm{~h}$, exceto o Cocó que exibiu conforto às $9 \mathrm{~h}$.

Destaca-se que na escala Te o desconforto configura-se às $9 \mathrm{~h}$ e na do INMET somente a partir das 11h. O ponto do Cocó é o único entre os analisados que segue uma tendência de se apresentar na faixa de conforto nas escalas, condição essa possível por sua expressiva área verde, presença insignificante de edificações, além da presença de superfície hídrica (rio Cocó), porém, é intrigante que essa situação não tenha se repetido na Sabiaguaba, área com grande índice vegetacional, com volume de massa edificada desprezível e presença do oceano, além da foz do rio Cocó.

Período tarde (13 às 18 horas)

Neste período o conforto apresentado no quadro 1 (A e B), gerado nos setores da pesquisa, é detectado situação de desconforto para todos os setores experimentais, a exceção ocorre entre as 15 e 17 horas para os pontos do Cocó, Aldeota e Beira-Mar. Às 17h é apresentado um quadro de inversão, do desconforto ao conforto, isso é detectado nas duas escalas consideradas. É estranha essa mudança, já que é nesse horário que se observa uma maior dinâmica da funcionalidade urbana (fluxo de veículos e pessoas, registrados simultaneamente aos de conforto). Cabe destacar que as áreas da Sabiaguaba e Mondubim registraram os mais elevados registros de vento com valores na Escala Beaufort de $4,3 \mathrm{~m} / \mathrm{s}$ até $11 \mathrm{~m} / \mathrm{s}$, apesar disso, esses ventos não garantiram conforto para essas áreas, tanto na escala do INMET como no índice Te.

Período noite (19 às 0 hora)

No índice Te (Quadro 1A) há predomínio de conforto. No entanto, entre as 18 e 20 horas existe situação de desconforto, estando os pontos da Aldeota, Sabiaguaba, Fátima, Henrique Jorge e Damas condicionados ao estresse ao calor. A condição de conforto na escala do INMET (Quadro 1B) é marcada sob a categoria de muita umidade, situação predominante por toda a madrugada. Às 19 e 20 horas ainda há registro de conforto para os pontos da Aldeota, Centro, Barra, Henrique Jorge e Mondubim para a escala do INMET estando os demais pontos sobre condição de muita umidade. O ponto da Sabiaguaba foi o único a apresentar no período da noite, às $19 \mathrm{~h}$, situação de desconforto.

A velocidade do vento durante esse período do dia se caracterizou pelo predomínio de calmaria ( 0 a $1 \mathrm{~m} / \mathrm{s})$, bafagem $(2,5 \mathrm{~m} / \mathrm{s}$ a $4,2 \mathrm{~m} / \mathrm{s})$ e aragem $(1,1 \mathrm{~m} / \mathrm{s}$ a $2,4 \mathrm{~m} / \mathrm{s})$. Os pontos que registraram os maiores valores desse elemento foram Sabiaguaba, Beira-Mar e Fátima. Essa situação garantiu em associação com as taxas de umidade condições de conforto e muita umidade para esses setores de acordo com as escalas do INMET e Te (Quadro 1A e B), exceto para a área da Sabiaguaba as 19 horas.

Período Madrugada (1 às 6 horas)

A condição de conforto na escala Te (Quadro 1A) foi presente para todos os pontos da pesquisa, ou seja, todas as áreas experimentais apresentaram valores dentro da categoria Zona de conforto $\left(21^{\circ} \mathrm{C}\right.$ a $26^{\circ} \mathrm{C}$ ). Já para a escala do INMET (Quadro 1B) houve situação de muita umidade para todo o período. 


\title{
EXPERIMENTO II (Primavera austral, representativo da quadra seca)
}

\author{
Período manhã (7 às 12 horas)
}

As configurações da temperatura e umidade do ar em associação com a velocidade do vento condicionaram condições de desconforto térmico nas duas escalas consideradas pela pesquisa, índice Te e Diagrama do Conforto INMET, para os horários de 9 às 12 horas (Quadro 2 A e B). Essa condição se configura a partir das 9 horas, se estendendo por todo o período da tarde, sendo que os pontos do Henrique Jorge e Damas exibem desconforto já a partir das $8 \mathrm{~h}$. Vale ressaltar que às $7 \mathrm{~h}$ não se registra nenhum evento de desconforto nos pontos experimentais da pesquisa.

Damas apresenta os maiores valores de desconforto na escala Te (Quadro $2 \mathrm{~A}$ ) com extremos de $28,2^{\circ} \mathrm{C}$ e $28^{\circ} \mathrm{C}$ para os horários de 11 e 12 horas, respectivamente. É válido lembrar que são nesses horários que se registraram as mais intensas ilhas de calor detectadas em Fortaleza (MOURA, ZANELLA, SALES, 2008; MOURA, 2008). A tendência do desconforto para esse ponto também é registrada na escala do INMET (Quadro 2B), com valores na categoria de Muito Quente, extrapolando a zona de desconforto da escala, para o período de 10 às 15 horas. Seguem também essa tendência os pontos do Mondubim e Alto Alegre.

Período tarde (13 às 18 horas)

O campo do conforto térmico na cidade apresenta condições de estresse ao calor para a maioria dos pontos experimentais da pesquisa. A escala Te exibiu uma maior freqüência de registros de desconforto do que a escala do INMET, como pode ser constatado no quadro 2. As taxas de desconforto vão cessar a partir das $17 \mathrm{~h}$ para o índice Te, enquanto para o Diagrama do INMET isso ocorre duas horas antes. $\mathrm{O}$ ponto do Damas segue com a tendência de exibir elevados valores de desconforto como $27,2^{\circ} \mathrm{C}$ às $13 \mathrm{~h}$ na escala Te, sendo o único ponto que exibiu condição de estresse ao calor até as $18 \mathrm{~h}$. Já o ponto do Mondubim apresenta altos índices de desconforto na escala do INMET, onde foi detectada condição Muito Quente para essa área entre as 13 e 15 horas. São pontos que registraram também altas taxas de desconforto para o período da tarde: Henrique Jorge e Alto Alegre, isso nas duas escalas de conforto.

Às 14 e 15 horas todos as áreas da pesquisa exibiram valores de desconforto na escala Te, fato talvez explicado pelas elevadas temperaturas, pois todos os pontos apresentaram temperaturas a partir de $29^{\circ} \mathrm{C}$ durante esses horários. O diagrama do INMET exibe já no período da tarde condição de conforto para os pontos da Lagoa, Cocó, Sabiaguaba, Aldeota e Beira-Mar, condicionado pelo vento em associação com temperaturas amenas, já que são nesses pontos que se registraram as mais elevadas taxas do fluxo do ar e os menores valores térmicos. Quanto ao vento, para esse período do dia, os valores oscilaram entre ventos muito frescos $(11,1 \mathrm{~m} / \mathrm{s}-13,7 \mathrm{~m} / \mathrm{s})$ a calmaria $(0-1 \mathrm{~m} / \mathrm{s})$. O ponto da Sabiaguaba apresentou as maiores taxas dessa variável meteorológica, registrando ventos de $11,1 \mathrm{~m} / \mathrm{s}$ a $13,7 \mathrm{~m} / \mathrm{s}$ para os horários de 13 as 18 horas, porém, essa condição não garantiu conforto de acordo com índice Te entre os horários de 13 às 15 horas, entretanto, no Diagrama do INMET, já há registros de conforto, como pode ser visto no quadro $2 \mathrm{~B}$. 
Período noite (19 às 0 hora)

As temperaturas desse período do experimento exibem homogeneidade em seus valores, pois para todas as áreas as taxas estão na categoria de $24^{\circ} \mathrm{C}$ a $28^{\circ} \mathrm{C}$. As áreas experimentais que apontaram para os mais reduzidos valores foram Alto Alegre, Cocó e Beira-Mar, não ultrapassando os $25,5^{\circ} \mathrm{C}$, o que permitiu, dessa maneira, em associação com as taxas de vento e umidade, condições de Muito Úmido para a escala do INMET e Conforto na escala Te para essas áreas da pesquisa. As condições de conforto (Quadro 2) se configuraram dentro da zona de conforto, tanto para a escala Te quanto para o INMET, isso para todas as áreas experimentais em todos os registros da noite. Salienta-se que essa situação térmica se estende por todo o período da madrugada.

Período Madrugada (1 às 6 horas)

Todas as áreas amostrais da pesquisa exibiram condições de conforto no período da madrugada, situação essa já estabelecida desde às $18 \mathrm{~h}$ na escala Te e às $16 \mathrm{~h}$ para o Diagrama do INMET. Valores na categoria de Muito Úmido na escala do INMET foram registradas com maior freqüência durante a madrugada para todas as áreas, sendo que o Alto Alegre demonstrou essa condição em todos os horários também da noite, exceto às $0 \mathrm{~h}$, conforme demonstra o quadro $2 \mathrm{~B}$.

$\mathrm{O}$ conforto térmico, concebido pelas as escalas Te e do INMET, de modo geral refletiram de perto as condições térmicas, higrométricas e aerolares obtidas nos experimentos do trabalho. Sendo que o Experimento I (Quadro 1) apresentou uma maior freqüência de registro de desconforto, além das maiores intensidades dos valores nas duas escalas consideradas. Essa informação vai ao encontro com o já detectado por Moura (2006), que afirma que é no período da quadra chuvosa na cidade que as condições de desconforto se elevam, condicionadas primordialmente pela redução dos ventos, altas taxas de nebulosidade e elevadas temperaturas.

O cenário de desconforto registrado durante o período chuvoso em Fortaleza reflete as condições de circulação atmosférica regional atuante sobre a cidade. A associação e dissipação de sistemas de baixa pressão atmosférica como foi o caso da ZCIT (Zona de Convergência Intertropical) e LI (linha de Instabilidade) no dia da realização do Experimento I são fatores limitantes para a produção do desconforto térmico.

A condição de desconforto para a escala Te foi registrada de forma mais nítida entre as 9 e 16 horas para todos os pontos nos dois experimentos da pesquisa, período esse que coincide com os maiores picos da temperatura do ar dos experimentos. A configuração do conforto nessa escala ocorre mais cedo para o Experimento II (quadra seca) às $18 \mathrm{~h}$ e somente às $21 \mathrm{~h}$ para o Experimento I. A partir desses horários se estabeleceu situação de conforto em todos os registros para todos os pontos experimentais da pesquisa.

As escalas de conforto exibiram compatibilidade nos seus valores, entretanto, enquanto a escala Te exibia categoria de conforto durante os registros noturnos e da madrugada, a escala INMET mostrava valores na categoria de Muito Úmido, isso ocorreu, talvez, por conta da escala Te se tratar de um índice matemático e a escala INMET de um diagrama.

\section{CONSIDERACÕES FINAIS}

As condições de conforto térmico na cidade de Fortaleza surgem como produto final de seus preditores, ou seja, a associação dos controles climáticos (sitio, estrutura e função urbana, somados às condições físico-naturais atuais do território) e dos atributos climáticos (temperatura, umidade e velocidade do ar), 


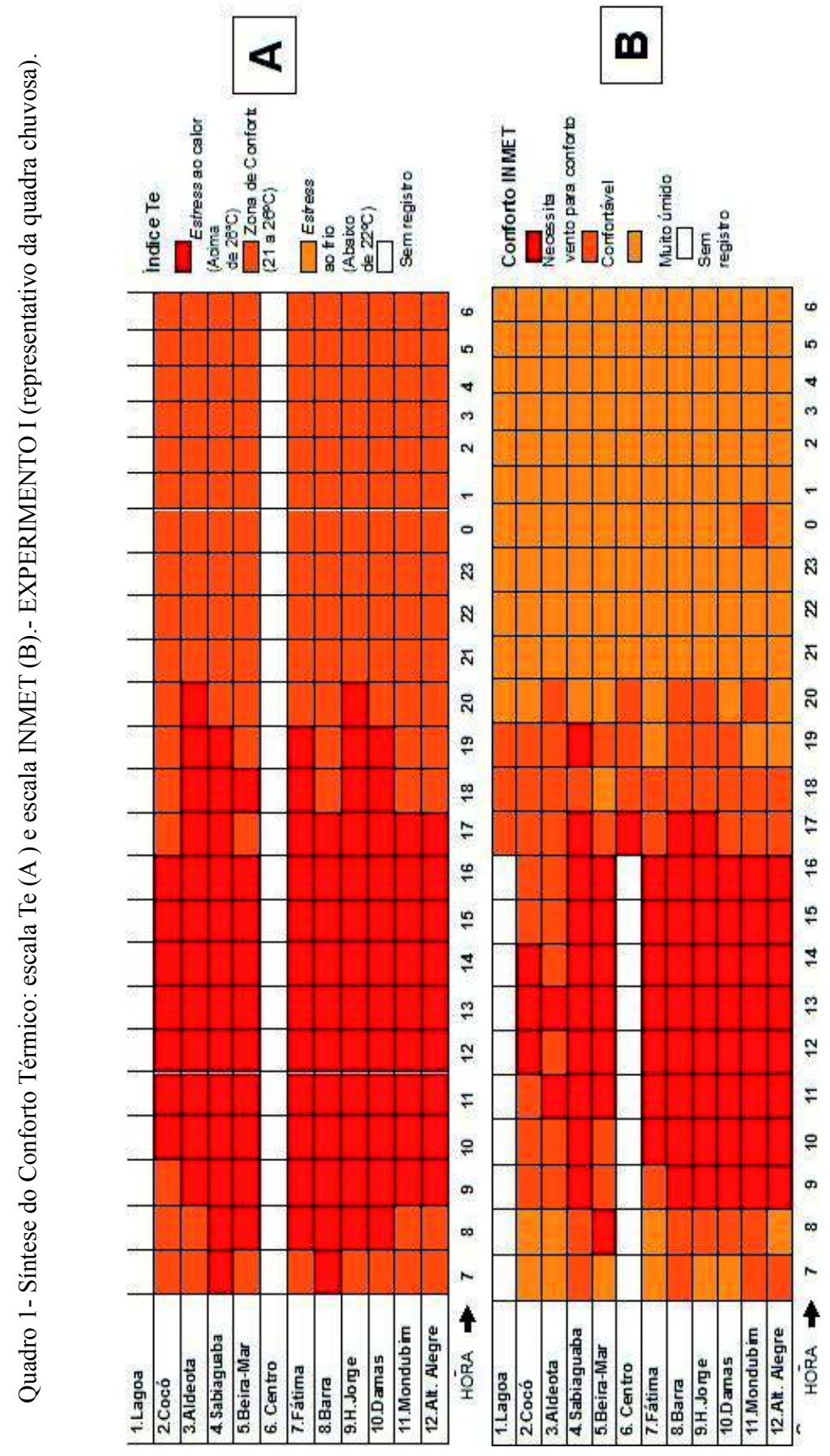

Revista da ANPEGE. v. 6, 2010 (jan./dez.) 


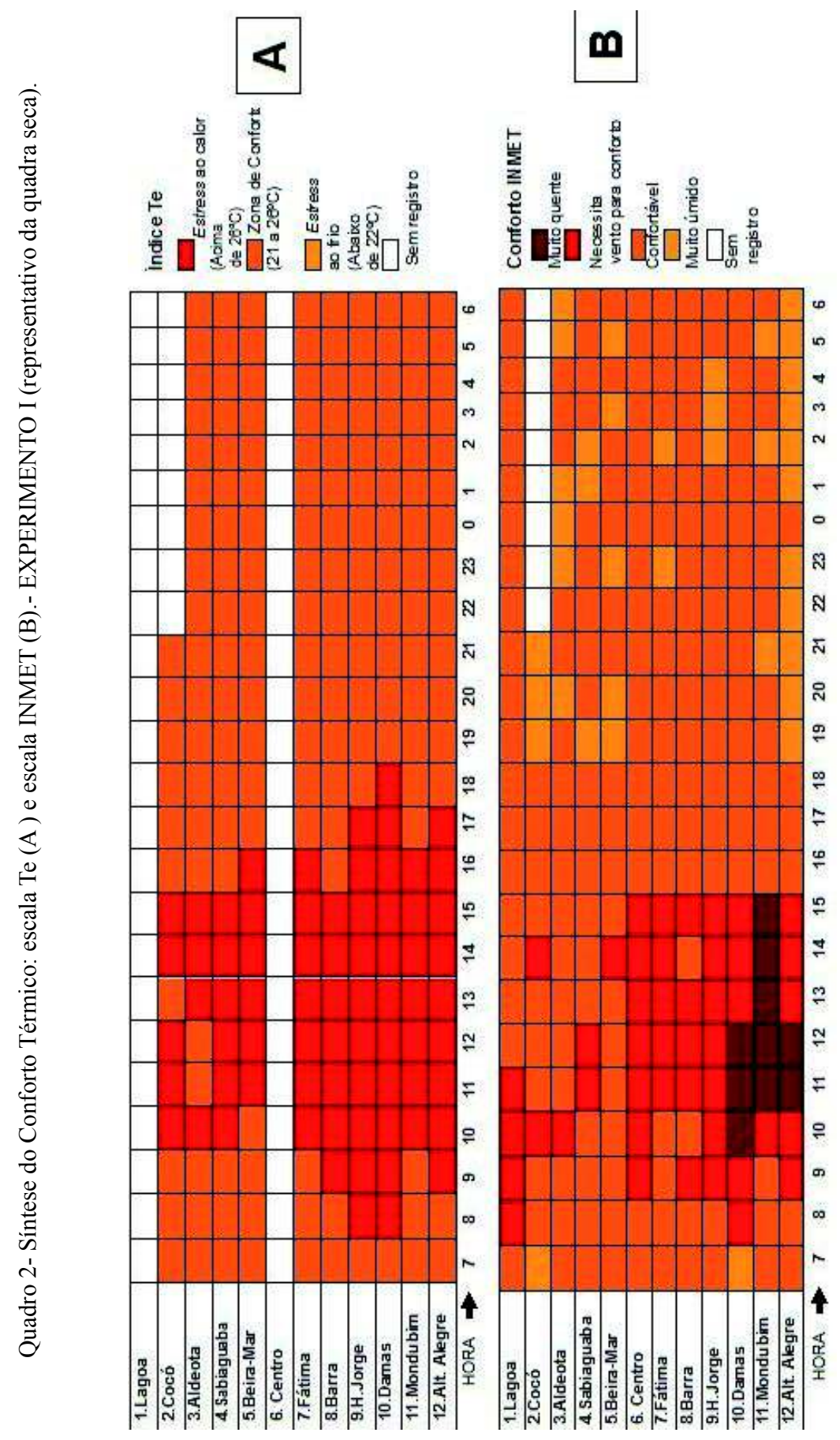


além dos condicionantes da circulação atmosférica regional que configuram os atributos climáticos locais. Ao analisar esses preditores de forma conjunta é possível obter um quadro geral, pelo menos genérico e parcial, das condições de conforto na cidade de Fortaleza, tendo como referência os experimentos realizados, esses representativos da habitualidade climática da cidade:

1) No período da manhã há condições de conforto para as horários de 7 e 8 horas, isso para as duas realidades sazonais (quadra chuvosa e seca), bem como para as duas escalas de conforto em análise. A exceção fica para as áreas dos bairros Damas e Henrique Jorge, situadas, respectivamente, na porção central e oeste da cidade, que apresentam já a partir das 8 horas estresse ao calor. São nessas áreas que se identificaram as mais freqüentes e intensas ilhas de calor em Fortaleza, segundo (MOURA, ZANELLA, SALES, 2008; MOURA, 2008);

2) É a partir das 9 horas que se configura cenário de desconforto pela cidade, condição essa que se estende ate às 17 horas. Para a escala do INMET essa condição se estabelece ate às 15 horas para o episódio representativo da quadra seca. Para esse recorte horário foram registradas temperaturas entre $26^{\circ} \mathrm{C}$ e $34^{\circ} \mathrm{C}$ e umidade relativa do ar na ordem de $50 \%$ a $70 \%$ para o Experimento I e de $35 \%$ a $65 \%$ para o Experimento II;

3) Os horários de 14 e 15 horas são os mais críticos, isso para a escala do Te em todas áreas experimentais. O exposto ocorre, possivelmente, pelas elevadas taxas de radiação incidente na superfície urbana de Fortaleza pela manhã e sua devolução à tarde com o pico máximo às $15 \mathrm{~h}$, podendo se estender até as $17 \mathrm{~h}$, como aconteceu no Experimento I, isso associado à complexa realidade do espaço urbano, na sua morfologia e funcionalidade;

4) A variável velocidade vento, elemento de primeira ordem na produção do conforto térmico não foi limitante para a garantia desse produto climático em muitos registros nas áreas da pesquisa. As taxas registradas por meio da escala Beaufort, para os períodos da manhã e tarde na ordem de $4,3 \mathrm{~m} / \mathrm{s}$ até $11 \mathrm{~m} / \mathrm{s}$ para o Experimento I e 4,3m/s até 13,7 m/s para o Experimento II, não foram, de modo geral, suficientes para geração do conforto;

5) Nos períodos da noite e madrugada, de forma geral, ocorreu condição de conforto para a escala Te e de Confortável e Muito Úmido para o INMET. No Experimento I essa situação ocorreu com taxas reduzidas de vento de $1 \mathrm{~m} / \mathrm{s}$ a $2,4 \mathrm{~m} / \mathrm{s}$, porém, há registro de desconforto em algumas áreas como Aldeota, Fátima, Henrique Jorge, Damas e Sabiaguaba para os horários de 18 e 20 horas;

6) A área do Damas apresenta, com maior freqüência, os maiores valores de desconforto com taxas superiores a $28^{\circ} \mathrm{C}$ para escala Te, além de se inserir na categoria de Muito Quente para a escala do INMET. $\mathrm{O}$ oposto ocorre no ponto do Coco, inserido na área do Parque do mesmo nome. Esse setor da pesquisa, de grande adensamento em área verde, revelou, com maior freqüência, os mais baixos valores na escala $\mathrm{Te}$, ou seja, esteve condicionada a faixa do conforto ou na categoria de Muito Úmido, isso devido aos controles climáticos ali inseridos.

É importante considerar que os valores elevados de desconforto térmico, geram condições de estresse para o calor na maior parte do dia em Fortaleza, o que influencia no bem estar das populações que circulam no ambiente urbano a pé ou das populações que trabalham em ambientes externos onde não há possibilidade do uso de refrigeração artificial, como os trabalhadores da construção civil. Estudos na área da medicina do trabalho mostram que trabalhadores de ambientes com estresse térmico positivo, a exemplo dos vendedores ambulantes, dentre outros, apresentam um índice nove vezes maior de contrair pedra nos rins. Sabe-se que mesmo as condições menos extremas de desconforto térmico também interferem na saúde, bem-estar e produtividade dos indivíduos. (NERY; ANDRADE; MOURA, 2006).

Revista da ANPEGE. v. 6, 2010 (jan./dez.) 
Deve-se considerar que nas áreas com elevadas temperaturas e desconforto térmico os gastos de energia para a produção de microclimas confortáveis são elevados, principalmente quando não existem preocupações em melhorar as condições ambientais das cidades por parte dos gestores públicos.

Alguns parâmetros urbanísticos poderiam ser utilizados para minimizar o estresse térmico positivo, no sentido de sombrear e ventilar mais o espaço urbano: a ampliação de áreas verdes; a manutenção de espaços abertos; a preservação dos corredores de ventos; e a inclusão de vegetação de porte para proteção da radiação solar, dentre outras. As considerações aqui expostas sobre o cenário do conforto térmico em Fortaleza não encerram a temática, apenas expõe que muito ainda precisa ser pesquisado, isso por conta da complexidade do objeto de estudo: as variáveis meteorológicas locais associadas à cidade na sua conjuntura de espaço urbano (sítio, morfologia e função urbana). Uma maior atenção deve ser ofertada a variável velocidade do vento, quanto ao instrumental, pois nesta pesquisa este elemento foi coletado de forma empírica através da Escala Beaufort, não oferecendo dados reais da variável o que comprometeu, em parte, a qualidade das analises associadas às escalas de conforto. Aplicações de diferentes escalas do conforto em distintas realidades temporais no espaço intra-urbano de Fortaleza seguido de testes estatísticos seriam essenciais para a eleição de uma escala adequada aos climas urbanos de cidades de clima tropical quente e úmido.

\section{REFERENCIAS BIBLIOGRAFICAS}

ANDRADE, H.O clima urbano- natureza, escalas de análise e aplicabilidade.Finisterra. Revista Portuguesa de Geografia ,XL, 80, p.66-91, 2005.

AYOADE, Introdução à climatologia para os trópicos. São Paulo: DIFEL, 1996. 332p.

BURIOL, G. A et al. Influência dos elementos meteorológicos no conforto térmico humano: bases biofísicas. In: Anais do VI Simpósio Brasileiro de Climatologia Geográfica. Aracaju/SE, 2004. CD ROM.

FORTALEZA. Mapas temáticos do Plano Diretor de Desenvolvimento Urbano e Ambiental, 2006. Disponível em <http:// www.seinf.fortaleza.ce.gov.br/PDDU-FOR. Acesso em 18 de novembro 2006.

FROTA, A. B; SCHIFFER, S.R. Manual do conforto térmico. São Paulo: Nobel, 1988.

HISSA, M.C. O estudo do conforto ambiental climático de edifícios multifamiliares em Fortaleza. (Dissertação de Mestrado). Fortaleza: Pós-Graduação Engenharia Civil/ UFC, 2000. 227p.

INMET. Diagrama do conforto humano. Disponível em www.inmet.gov.br. Acesso em 22 de abril de 2006.

MAIA, L.P et al. Alterações climáticas na região de Fortaleza causada por fatores naturais e antrópicos. Revista de Geologia UFC. Fortaleza, vol. 9, p.111- 121, 1996.

MONTEIRO, C. A. F. Teoria e Clima Urbano. Série Teses e Monografias, n²5. São Paulo: Instituto de Geografia/ USP, 1976.

MOURA, M. O. Os microclimas urbanos de Fortaleza: ritmos episódicos em duas áreas representativas da cidade. (Relatório de Graduação). Fortaleza: Departamento de Geografia/UFC, 2006. 168p.

MOURA, M. O. O clima urbano de Fortaleza sob o nível do campo térmico. (Dissertação de Mestrado). Fortaleza: Programa de Pós- Graduação em Geografia/UFC, 2008. 318p.

MOURA, M. O.; ZANELLA, M .E; SALES, M. C. L. Ilhas térmicas na cidade de Fortaleza/CE. Boletim Goiano de Geografia, vol.28, n.2, jul-dez, Goiânia, p.33-44, 2008. 
NERY, J.; ANDRADE, T.; MOURA, T. Conforto térmico em Salvador: o índice PET e sua abordagem projetual. RUA (Revista de Arquitetura e Urbanismo- UFBA), vol.7, n.1, Salvador, p.70-77, 2006.

NIEUWOLT, S. Tropical Climatology. New York: Jonh Wiley \& Sons, 1977. 208p.

RORIZ, M. Flutuações horárias dos limites de conforto térmico: uma hipótese de modelo adaptativo. In: Anais do VII Encontro Nacional sobre Conforto no Ambiente Construído (ENCAC). Curitiba, PR. 2003.

SANTANA, A. M. S. A forma urbana e a radiação solar incidente na criação das ambiências térmicas e seus reflexos na apropriação e uso dos espaços públicos externos. (Tese de Doutorado). São Paulo: FFLCH/USPPrograma de Pós-Graduação em Geografia, 2002. 292p.

XAVIER, T. de Ma. B. S. Tempo de Chuva - estudos climáticos e de previsão para o Ceará e o Nordeste Setentrional. Fortaleza: ABC Editora, 2001. 478p.

Recebido em agosto 2010

Aceito em dezembro de 2010

Revista da ANPEGE. v. 6, 2010 (jan./dez.) 